\title{
Preferences for Distributional Impacts of Climate Policy
}

\section{Svenningsen, Lea Skræp; Thorsen, Bo Jellesmark}

\section{Published in:}

Environmental and Resource Economics

Link to article, DOI:

$10.1007 / \mathrm{s} 10640-019-00386-\mathrm{z}$

Publication date:

2020

Document Version

Early version, also known as pre-print

Link back to DTU Orbit

Citation (APA):

Svenningsen, L. S., \& Thorsen, B. J. (2020). Preferences for Distributional Impacts of Climate Policy. Environmental and Resource Economics, 75, 1-24. https://doi.org/10.1007/s10640-019-00386-z

\section{General rights}

Copyright and moral rights for the publications made accessible in the public portal are retained by the authors and/or other copyright owners and it is a condition of accessing publications that users recognise and abide by the legal requirements associated with these rights.

- Users may download and print one copy of any publication from the public portal for the purpose of private study or research.

- You may not further distribute the material or use it for any profit-making activity or commercial gain

- You may freely distribute the URL identifying the publication in the public portal

If you believe that this document breaches copyright please contact us providing details, and we will remove access to the work immediately and investigate your claim 
This is a pre-print version of the paper to be cited as:

Svenningsen, L.S. and B.J. Thorsen, 2019: Preferences for distributional impacts of climate policy. Environmental and Resource Economics, online first: DOI: 10.1007/s10640-019-00386-z 


\title{
Preferences for distributional impacts of
}

\section{climate policy}

\begin{abstract}
What role do people think distributional aspects should play in design of climate policy? The literature assessing climate policies has shown that assumptions regarding peoples' distributional preferences for climate change policy impacts are central for policy assessment, but empirical evidence for such preferences is lacking. We design a discrete choice experiment that varies how climate policies affect the income of people living in the future in three geographical regions, with distinctly different current and future income levels. The experiment is implemented on a sample of the Danish population and preferences are modelled in a latent class model. Our results show that we cannot reject the hypothesis that a small majority of the sample $(60 \%)$ hold preferences consistent with inequity aversion with respect to future income effects of climate policies across regions. For the same group we find that preferences for co-benefits for current generations reflect a form of altruism, but not inequity aversion. In both cases, the altruistic aspects are moderated by an element of preferences for positive outcomes in own region too. The remaining classes display preferences with a varying focus on impacts in their own region or simply no support for further climate policy Our results provide some support for the inclusion of social preferences regarding distributional effects of climate change policies in policy assessments, and hence for the significant impact on policy this inclusion will have.
\end{abstract}

Keywords: choice experiment, social preferences, inequity aversion, altruism, climate change impacts, latent class, social cost of carbon.

JEL Classification: D30, H41, Q51, Q54

Acknowledgements: The authors are grateful to two reviewers and the associate editor for helpful comments that improved the paper. We thank Frank Jensen for inspiring the theoretical framework and participants at EAERE 2017, Athens, for several good suggestions. Thorsen acknowledge the support of the Danish National Research Foundation (DNRF Grant 96) for Center for Macroecology, Evolution and Climate. 


\section{INTRODUCTION}

Climate change remains a daunting challenge facing the global community. Since the emergence of the first IPCC reports, a fast growing body of research has focused on modelling and predicting the future consequences of climate change for human societies. A key finding is that the future impacts of climate change are likely to be felt unevenly around the globe. Societies and people in developing countries may be more susceptible to negative impacts of climate change, due to both geographical and climatic contexts as well as adaptive capacity (IPCC 2014). Governments around the world are ratifying the Paris Agreement (UNFCC 2016 ${ }^{1}$ ) and are reporting national goals for their respective emission levels. In that process, the question of whether and how to account for global impacts of policies, herein the impact $\mathrm{CO}_{2}$ emissions can have on others, becomes pertinent for designing national climate policies (Anthoff and Tol 2010). The answer will affect the costs a nation would be willing to carry to reduce $\mathrm{CO}_{2}$ emissions.

The utility effect of a specific absolute loss of income will in general not be the same to a poor person as to a rich. Integrated assessment models used to assess the marginal social costs of carbon emissions (SCC) often handle this aspect using equity weights of some form. This implies weighing together the monetized welfare (income) losses from climate change across regions of disparate incomes, under the assumption of a supranational social planner (Fankhauser, Tol et al. 1997, Pearce 2003, Johansson-Stenman 2005, Anthoff, Hepburn et al. 2009). However, in the absence of this supranational planner, how should national policy makers account for climate change impacts in other countries? One could argue that this should depend on local, national preferences over global impacts. Anthoff and Tol (2010) points out, that it is unusual in national policy assessments in general to take into account the impacts a national policy may have on citizens of other countries. In their paper, they develop a handful of alternative models for how a national government may account - or not - for welfare losses in other countries resulting from national policies. They show that varying assumptions about the concern for others have significant impact on what costs a national government would be willing to carry.

Our paper addresses the question whether people's preferences over climate policy alternatives vary according to how the policy affects the income of people of disparate wealth living in the future. There is a substantial body of evidence in the behavioral economics literature that people exhibit

\footnotetext{
${ }^{1}$ http://unfccc.int/paris_agreement/items/9444.php
} 
varying degrees of other-regarding/social preferences when placed in different experimental contexts (Andreoni 1990, Fehr and Schmidt 1999, Bardsley and Sugden 2006, Fehr and Schmidt 2006, Andreoni and Harbaugh 2007, Fischbacher and Gachter 2010). However, none have investigated if such preferences are relevant in the intergenerational context of climate policy design ${ }^{2}$.

The core contribution of this paper is an experiment designed to enable explicit evaluation of hypotheses about the presence of intergenerational social preferences for distributive impacts in the context of climate policy. Building on Anthoff and Tol (2010), we formulate and evaluate two different hypotheses regarding preferences over climate policy impacts. Specifically, we investigate for the presence of preferences consistent with the idea that climate policy design should take into account inequity aversion, and we call this type 'Inequity Averse Altruists'. We also investigate for preferences corresponding to individuals preferring climate policies that reduce aggregate impacts on future generations' income, but with no attention to who experience these impacts. We call this type simply 'Altruists'. We note that preferences of many other forms may exist and indeed co-exist in any population.

We implemented the experiment on a sample of the Danish population $(\mathrm{N}=813)$ and modelled preferences in a latent class model. Our main result is the finding that we cannot reject the hypothesis that a small majority of the sample $(60 \%)$ hold preferences consistent with the type Inequity Averse Altruists with respect to future income effects of climate policies across regions. For the same group we find that preferences over co-benefits for current generations reflect the Altruist type. This result provides some support for the inclusion of distributional preferences in some form in the social cost of carbon literature. The behaviour of the remaining groups however also indicates diverse preference heterogeneity for climate policy. We identify a group (17\%) mainly interested in securing co-benefits in their own region and a small group $(6 \%)$ preferring not to support additional climate policies. Finally, we find a group that expresses some form of support for climate policies, with focus on income and co-benefits in own region. However, for this last group we estimate a negative marginal utility of income, perhaps reflecting some form of strategic behaviour in signalling support to climate policies. Our results thus highlight the heterogeneous nature of preferences for climate policy in general, illustrating the often identified locational preference for climate policy co-benefits.

\footnotetext{
${ }^{2}$ Other authors have pursued what determines the publics willingness to pay to mitigate climate change, such as the paper by Diederich and Goeschl (2014) but the authors do not focus on the explicit question of intergenerational equity and the choice of climate policy.
} 
The remainder of this article is structured as follows. The next section reviews the related literature and Section 3 introduces a formal utility framework and its integration into our econometric specification. Section 4 describes the methods and materials and Section 5 presents the results. Section 6 discusses and concludes.

\section{RELATED LITERATURE}

The literature on modeling the economic impact of climate change has for many years debated the use of equity weights, which essentially account for the distributional impacts of climate change (Fankhauser, Tol et al. 1997, Pearce 2003, Johansson-Stenman 2005, Anthoff, Hepburn et al. 2009, Anthoff and Tol 2010). One of the critical assumptions in this literature is the presence of a global social planner. As an extension to this literature, Anthoff and Tol (2010) introduced the notion that national policymakers could design policies in accordance with the degree of concern for climate change impacts in other countries present in the population of their country. They investigated how different forms of such other-regarding preferences would influence the optimal level of climate policy in different countries ${ }^{3}$. They find that when a nation is concerned about impacts in other countries and regions, this influences their willingness to pay for emissions reductions, with varying effect across the countries and regions they include in their analysis. Thus, the role of social preferences over distributive impacts does not appear to be trivial from neither a theoretical nor a policy point of view.

The relevance of social preferences over distributive outcomes can both be established as a normative criterion for behavior (Grubb 1995, Konow 2001, Ikeme 2003) as well as a description of actual behavior, as found in the behavioral and experimental economics literature. Several papers and models have been developed to explain the other-regarding/altruistic behavior of agents, e.g. that agents often do exhibit varying degrees of social preferences, and are willing to sacrifice some of their own payoff to the benefit of others (Andreoni 1990, Fehr and Schmidt 1999, Bardsley and Sugden 2006, Fehr and Schmidt 2006, Andreoni and Harbaugh 2007, Fischbacher and Gachter 2010).

\footnotetext{
${ }^{3}$ Anthoff and Tol (2010) did not explicitly label their categorization as social preferences, but as different attitudes towards equity and justice. They introduced different concerns regarding the distributional impacts in other regions; which they called 'sovereignty', 'altruism', 'good-neighbour' and 'compensation'.
} 
An important aspect from this literature is that several different forms of social preferences might be relevant and present in any given context (Engelmann and Strobel 2004, Burlando and Guala 2005, Cappelen, Hole et al. 2007, Clément, Rey-Valette et al. 2015).

We are not the first to study social preferences in relation to climate change and climate change policies as such. Previous examples include the investigation of the preferences of negotiators involved in the international negotiations on climate change (Lange, Vogt et al. 2007, Dannenberg, Sturm et al. 2010) and people's preferences over the distribution of the costs of CO2 mitigation (Cai, Cameron et al. 2010, Carlsson, Kataria et al. 2012). Theoretical papers have studied the use of equity weights and general inequity aversion models (Pearce 2003, Anthoff, Hepburn et al. 2009, Anthoff and Tol 2010, Kverndokk, Nævdal et al. 2014) and the role of social norms for climate policy preferences (Alló and Loureiro 2014). Note that none of these studies explicitly addressed the aspect of intergenerational equity concerns in climate policy preferences.

A fundamental feature in the literature on climate policy preferences is what constitutes the outcome provided by a climate policy. In this study, we have opted for an aggregation of impact into income measures in different regions. In the literature, preventing changes in temperature and accompanying changes to ecosystems etc. have been used as attributes (Johnson and Nemet 2010). Another dimension is the physical placement of the policy outcome where both local (Berk and Fovell 1999, Layton and Brown 2000, Viscusi and Zeckhauser 2006) and global expected climate change impacts (Carlsson, Kataria et al. 2012) have been used as climate policy outcomes for which to elicit peoples willingness to pay (WTP). Thus, a large diversity exists in the approaches to eliciting WTP for climate policies and their outcomes, and our choice derives from our focus on equity aspects.

Climate mitigation policies often generate local co-benefits ${ }^{4}$, and this aspect is included in the experimental design as well. Several studies found that co-benefits may affect peoples' willingness to support climate policies (MacKerron, Egerton et al. 2009, Longo, Hoyos et al. 2012, RodríguezEntrena, Espinosa-Goded et al. 2014, Torres, MacMillan et al. 2015). We included a regional cobenefit for current generations of implementing climate mitigation policies in the region and this

\footnotetext{
${ }^{4}$ Examples could be cleaner or safer energy, resulting in improved health outcomes, or it may be changed land uses reducing erosion issues or biodiversity losses.
} 
allows us to investigate, as a side issue, whether people express social preferences for the physical placement of the mitigation policy and hence associated regional co-benefits.

\section{THEORY}

In this section, we develop a theoretical framework for our two social preference types; Inequity Averse Altruists and Altruists and derive a foundation for our empirical model. The model we construct is based on the premise of an agent living today (we call this period 1), who can choose to invest in climate policies that will have an effect both in the agents' own life time (period 1) and for future generations (we call this period 2).

We interpret the overall problem faced by respondents in our study as an income allocation problem. By a simplifying assumption, respondents decide how much income to allocate to different climate policies $^{5}$. The income that an agent will allocate to a given climate change policy is a function of two additive but separable utility components; 1) the utility resulting from co-benefits generated by climate policies which influence present generations and 2) the utility associated with the resulting income-changes for future generations affected by climate change. This implies that we consider the utility, $U$, of a representative agent to be composed of two additive sub-utility functions; $U_{1}$ which captures the utility generated by period 1 co-benefits and $U_{2}$ which captures utility from period 2 income effects. We assume two non-overlapping periods and that the representative agent lives in time period 1, but gains utility from both period 1 and 2 outcomes.

In our model, a representative consumer allocates a given level of income to climate change policies in period 1 which is labelled $y_{1}$. Assume that climate policy will influence three regions; Western Europe (WE), Southeast Asia (SEA) and Sub-Saharan Africa (SSA). In all three regions, climate policy will reduce the expected loss in income for future generations resulting from climate change

\footnotetext{
${ }^{5} \mathrm{We}$ acknowledge that this is a narrow definition of the general income allocation problem that agents face. The general allocation of income between different goods could be handled in a two-stage budgeting model which can handle that agents have a range of different goods they wish to allocate their overall income on. However, as we wish to develop a model of preferences in relation to climate policy, we abstract from the general, underlying income allocation problem and focus directly on the income allocated to climate policy, thus assuming that the general allocation of income to different goods (among here climate policy) has already taken place.
} 
and generate co-benefits for the present generation, in the region where mitigation policies are implemented.

We let $I L_{i}^{2}$ for $i=W E, S E A, S S A$ denote the period 2 loss in income resulting from climate change in WE, SEA and SSA, while $C O B_{i}^{1}$ for $i=W E, S E A, S S A$ denote the period 1 co-benefit in either WE, SEA or SSA, and $y_{i}^{1}$ be the income allocated to policies affecting each region in time period 1. The income a consumer would allocate to policies affecting each region is a function of the income loss and co-benefit of the specific policy option, implying that $y_{i}\left(I L_{i}, C O B_{i}\right)$. We assume that the income allocation represents real market behavior, so the representative consumer cannot allocate more income than $y_{1}$. This implies that the following budget restriction must be satisfied

$y_{1}=y_{W E}^{1}\left(I L_{W E}^{2}, C O B_{W E}^{1}\right)+y_{S E A}^{1}\left(I L_{S E A}^{2}, C O B_{S E A}^{1}\right)+y_{S S A}^{1}\left(I L_{S S A}^{2}, C O B_{S S A}^{1}\right)$

Thus, the sum of allocated income to policies affecting the three regions cannot exceed the total income allocated to climate policies.

As mentioned, we assume the overall utility function for a representative agent to be composed of two additive, separable sub-utility functions, capturing that income allocated to climate policy now has immediate effect in the form of co-benefits (captured by $U_{1}$ ) and a future effect on the expected income loss from climate change (captured by $U_{2}$ ):

$U=U_{1}+U_{2} \Rightarrow U=U_{1}\left(C O B_{W E}^{1}, C O B_{S E A}^{1}, C O B_{S S A}^{1}\right)+U_{2}\left(I L_{W E}^{2}, I L_{S E A}^{2}, I L_{S S A}^{2}\right)$

For an agent that derive utility from the provision of co-benefits in period 1 for herself or others, we assume $\frac{\partial U_{1}}{\partial \operatorname{COB}_{i}^{1}}>0$, and similarly for an agent that experience a loss of utility from income losses arising for future generations in her own or other regions, we assume $\frac{\partial U_{2}}{\partial I L_{i}^{2}}<0$ for $i=W E, S E A, S S A$.

The maximization problem requires solving the Lagrange function:

$L U=U_{1}\left(C O B_{W E}^{1}, C O B_{S E A}^{1}, C O B_{S S A}^{1}\right)+U_{2}\left(I L_{W E}^{2}, I L_{S E A}^{2}, I L_{S S A}^{2}\right)+\lambda\left(y_{1}-y_{W E}^{1}\left(I L_{W E}^{2}, C O B_{W E}^{1}\right)-\right.$

$\left.y_{S E A}^{1}\left(I L_{S E A}^{2}, C O B_{S E A}^{1}\right)-y_{S S A}^{1}\left(I L_{S S A}^{2}, C O B_{S S A}^{1}\right)\right)$

Here the multiplier $\lambda$ is interpreted as the marginal utility of income. Using $\operatorname{COB}_{W E}^{1}, \operatorname{COB}_{S E A}^{1}$ and $C O B_{S S A}^{1}$ as control variables for period 1 utility $U_{1}$ and $I L_{W E}, I L_{S E A}$ and $I L_{S S A}$ as control variables for period 2 utility $U_{2}$, yield the following pairs of first-order conditions for $i=W E, S E A, S S A$ : 


$$
\begin{aligned}
& \frac{\partial U_{2}}{\partial I L_{i}^{2}}-\lambda \frac{\partial y_{i}^{1}}{\partial I L_{i}^{2}}=0 \\
& \frac{\partial U_{1}}{\partial C O B_{i}^{1}}-\lambda \frac{\partial y_{i}^{1}}{\partial \operatorname{COB}_{i}^{1}}=0
\end{aligned}
$$

The first term on the left-hand side of each of the first order conditions captures the marginal utility for the agent from experiencing the outcomes of the policy in the form of a marginal increase in income loss or co-benefits in the different regions. The second term captures the marginal utility of income $(\lambda)$ that is given up to pay for the policy.

The first-order conditions in (4) - (5) can be reduced to yield two pairs of equations of the form:

$\frac{\partial U_{2}}{\partial I L_{i}^{2}} / \frac{\partial y_{i}^{1}}{\partial I L_{i}^{2}}=\lambda$ and $\frac{\partial U_{1}}{\partial C O B_{i}^{1}} / \frac{\partial y_{i}^{1}}{\partial C O B_{i}^{1}}=\lambda$

Here $i$ again denote the three different regions. This reduced first order condition states that in optimum the marginal utility from a climate policy outcome change relative to the marginal allocation of income to support that outcome change (reduced income loss, co-benefits) must equal the marginal utility of income, $\lambda$.

We now turn to our two social preference types, Inequity Averse Altruists and Altruists, and their characteristics within this framework. Before doing that we make explicit the assumption that future generations in WE will be richer than the future generations in SEA, which again will be richer than those in SSA. Agents are consistently informed about this during the survey. Furthermore, we discuss the implications of the agent living in one of the regions.

\section{$\underline{\text { Inequity Averse Altruists }}$}

In economic analysis it is common to separate efficiency and distributional concerns, but we propose that agents might have preferences for distributional outcomes of climate policies and prefer climate polices that takes this into account. The Inequity Averse Altruist observes the principle of declining marginal utility of income and hence that a marginal reduction in income loss may be worth more to the poor than to the rich. An agent conforming to the Inequity Averse Altruist type will derive higher utility from a marginal reduction in income loss for those that are less well of, than for those that are better off. This form of inequity aversion is the one most commonly found in the social cost of carbon literature. In addition to the preference for future distributional outcomes of climate policy, the Inequity Averse Altruist may also prefer a marginal increase in co-benefits be provided to the less 
well-off than the well-off regions. Assuming only these altruist preferences regarding outcome this implies the following restrictions on the form of the utility function:

$\frac{\partial U_{2}}{\partial I L_{W E}^{2}}<\frac{\partial U_{2}}{\partial I L_{S E A}^{2}}, \frac{\partial U_{2}}{\partial I L_{W E}^{2}}<\frac{\partial U_{2}}{\partial I L_{S A}^{2}}$ and $\frac{\partial U_{2}}{\partial I L_{S E A}^{2}}<\frac{\partial U_{2}}{\partial I L_{S S A}^{2}}$

and

$\frac{\partial U_{1}}{\partial C O B_{W E}^{1}}<\frac{\partial U_{1}}{\partial C O B_{S E A}^{1}}, \frac{\partial U_{1}}{\partial C O B_{W E}^{1}}<\frac{\partial U_{1}}{\partial C O B_{S S A}^{1}}$ and $\frac{\partial U_{1}}{\partial C O B_{S E A}^{1}}<\frac{\partial U_{1}}{\partial C O B_{S S A}^{1}}$

These conditions imply that an Inequity Averse Altruist agent will allocate more income to (buying) climate policies that favor SSA over SEA and WE. We are in particular interested in the inequity aversion related to the outcome affecting future generations, but our theoretical framework also allow the inequity averse pattern for the preference for co-benefits provided to the current generations. However, if the agent lives in one of the regions, then they may associate changes in co-benefits with direct utility benefits for themselves and their families. Similarly, they may derive bequest values from enhancing future incomes of their children's children in their own region. If they are young enough, they may even worry about impact on their own life time income. For agents living in WE, the implication is that inequity aversion would have to dominate these two additional utility drivers, if the inequities in eq. (7) involving WE should hold, whereas the inequities involving SEA and SSA will be enough to identify the type with respect to either of the outcome variables, if they hold.

\section{$\underline{\text { Altruists }}$}

We define the simpler Altruist type as an individual concerned with securing the highest aggregate future income across the three regions, through his/hers allocation of income to climate policy, placing no importance to the distributional outcome. Likewise, the Altruist is agnostic about who receives the co-benefit, but derives an altruist utility from the co-benefit being delivered. This implies the following restriction on the form of the utility function:

$\frac{\partial U_{2}}{\partial I L_{W E}^{2}}=\frac{\partial U_{2}}{\partial I L_{S E A}^{2}}=\frac{\partial U_{2}}{\partial I L_{S S A}^{2}}$ and $\frac{\partial U_{1}}{\partial C O B_{W E}^{1}}=\frac{\partial U_{1}}{\partial C O B_{S E A}^{1}}=\frac{\partial U_{1}}{\partial C O B_{S S A}^{1}}$

Again, as above, the agent may live in one of the regions and derive direct utility from co-benefits in their own region and bequest values for future generations in their own regions. If this is true for agents living in WE, only the equality involving SSA and SEA will be useful for identification.An Empirical Specification 
This subsection integrates the general model in the empirical model. We assume a functional form for our utility functions in eq. (2) $U_{1}$ and $U_{2}$, identical to that used in our econometric model. Specifically, the utility of a climate change policy is assumed to be a simple linear additive function of the marginal change in any of the six variables affected by climate policy; co-benefits and income losses arising in the three regions, as well as the cost of that policy to the agent:

$U=\frac{\partial U_{1}}{\partial C O B_{W E}^{1}} \times C O B_{W E}^{1}+\frac{\partial U_{1}}{\partial C O B_{S E A}^{1}} \times C O B_{S E A}^{1}+\frac{\partial U_{1}}{\partial \operatorname{COB}_{S S A}^{1}} \times C O B_{S S A}^{1}+\frac{\partial U_{2}}{\partial I L_{W E}^{2}} \times I L_{W E}^{2}+\frac{\partial U_{2}}{\partial I L_{S E A}^{2}} \times$

$I L_{S E A}^{2}+\frac{\partial U_{2}}{\partial I L_{S S A}^{2}} \times I L_{S S A}^{2}+\lambda \times \cos t$

Note that with this specification the marginal rate of substitution between an improvement in any of the six variables and income allocated for the consumption of any other good can be obtained, as exemplified by $\frac{\partial U_{1}}{\partial \operatorname{COB}_{i}^{1}} / \lambda$. From (6) we get $\frac{\partial U_{1}}{\partial \operatorname{COB}_{i}^{1}} / \lambda=\frac{\partial U_{1}}{\partial \operatorname{COB}_{i}^{1}} / \frac{\partial U_{1}}{\partial \operatorname{COB}_{i}^{1}} / \frac{\partial y_{i}^{1}}{\partial \operatorname{COB}_{i}^{1}}=\frac{\partial y_{i}^{1}}{\partial \operatorname{COB}_{i}^{1}}$. This last term can be interpreted as the individual's willingness to pay (WTP) for a marginal increase in co-benefits in region $i$.

Define for each region $i$ two variables, $\frac{\partial U_{1}}{\partial \operatorname{COB}_{i}^{1}}=\delta_{i}$ and $\frac{\partial U_{2}}{\partial I L_{i}^{2}}=\beta_{i}$, which can be inserted into eq. (9): $U=\delta_{W E} \times C O B_{W E}^{1}+\delta_{S E A} \times C O B_{S E A}^{1}+\delta_{S S A} \times C O B_{S S A}^{1}+\beta_{W E} \times I L_{W E}^{2}+\beta_{S E A} \times I L_{S E A}^{2}+\beta_{S S A} \times$ $I L_{S S A}^{2}+\lambda \times \operatorname{cost}$

The two social preference types can now be identified through the following tests regarding the relationship the coefficients for future income effects $(\beta)$ and the coefficients for present co-benefits $(\delta)$.

\section{Hypothesis 1}

For the Inequity Averse Altruists, three WTP inequities reflecting inequity aversion about future income outcomes can be evaluated:

$$
\left|\beta_{W E} / \lambda\right|<\left|\beta_{S E A} / \lambda\right|,\left|\beta_{W E} / \lambda\right|<\left|\beta_{S S A} / \lambda\right| \text { and }\left|\beta_{S E A} / \lambda\right|<\left|\beta_{S S A} / \lambda\right|
$$

Similarly, inequity aversion regarding the WTP for co-benefit outcome for current generations:

$$
\left|\delta_{W E} / \lambda\right|<\left|\delta_{S E A} / \lambda\right|,\left|\delta_{W E} / \lambda\right|<\left|\delta_{S S A} / \lambda\right| \text { and }\left|\delta_{S E A} / \lambda\right|<\left|\delta_{S S A} / \lambda\right|
$$

We stress that, as discussed above, because our Danish respondents live in WE, the inequities involving WE may not hold, even if respondents are inequity averse. However, if they do, then inequity aversion is strong enough to dominate other utility components. Nevertheless, identification 
of inequity aversion in either of the two outcome variables may hinge on the inequities involving SEA and SSA only. We test these inequalities explicitly and the hypotheses that WTP of an Inequity Averse Altruist is impacted more by income losses and/or co-benefits in a poorer region, as compared to a richer region, to a statistically significant degree in Section 5.

\section{Hypothesis 2}

For the Altruists, three WTP inequities reflecting inequity aversion about future income outcomes can be evaluated:

$$
\left|\beta_{W E} / \lambda\right|=\left|\beta_{S E A} / \lambda\right|,\left|\beta_{W E} / \lambda\right|=\left|\beta_{S S A} / \lambda\right| \text { and }\left|\beta_{S E A} / \lambda\right|=\left|\beta_{S S A} / \lambda\right|
$$

Similarly, the same altruistic trait could result in the WTP for co-benefit outcome for current generations to be:

$$
\left|\delta_{W E} / \lambda\right|=\left|\delta_{S E A} / \lambda\right|,\left|\delta_{W E} / \lambda\right|=\left|\delta_{S S A} / \lambda\right| \text { and }\left|\delta_{S E A} / \lambda\right|=\left|\delta_{S S A} / \lambda\right|
$$

Again, the effect of the agent living in WE implies that identification of the Altruist may hinge on the inequities involving SEA and SSA only.

Since the main purpose of this paper is to investigate social preferences in relation to the future distributive impacts of climate change, our main purpose is to evaluate the hypotheses of Inequity Averse Altruists and Altruists with respect to the future income effects, but we also evaluate the hypotheses for co-benefits.

\section{MATERIALS AND METHOD}

\subsection{The case study and survey design}

Due to the stock pollutant nature of carbon in the atmosphere and the slow adjustment of numerous physical mechanisms and ecological processes, it is common in the scientific literature to discuss the consequences of climate change, and hence climate change policies, over quite long time horizons. Often the year 2100 is a measure milestone (IPCC 2014) and we adopt this practice in our study, as we describe the effects of current climate policies for the income of people living in year 2100. In addition to the future impacts, we also include present benefits of climate policy in the form of cobenefits, generated from mitigation effort. 
The study focuses on three different regions of the world, Western Europe, Southeast Asia and SubSaharan Africa, as depicted in Figure1.

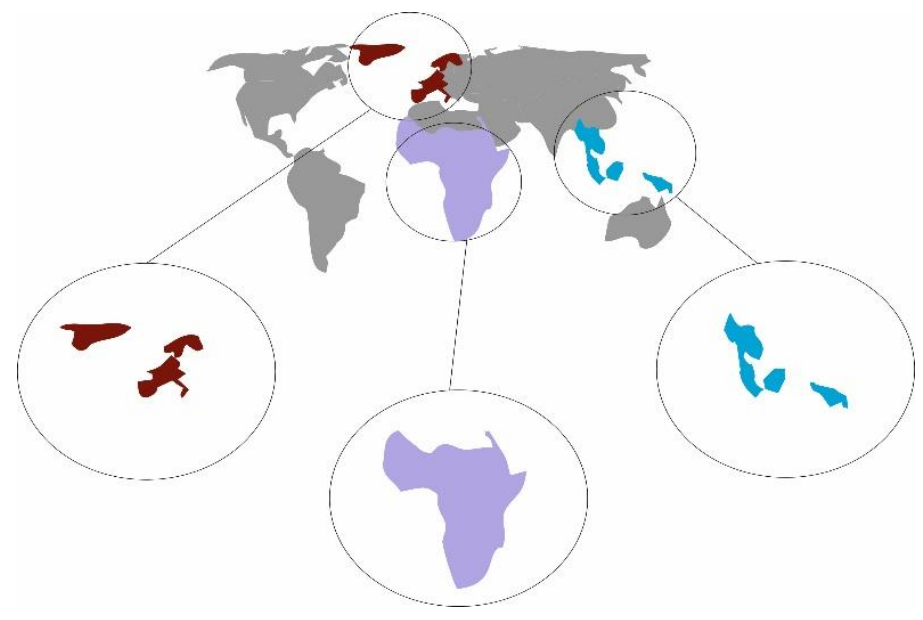

Figure 1. Visual representation of the three regions, as it was displayed to respondents in the survey

These three regions are typical regions used in the literature, including the model in Anthoff and Tol (2010).

The attribute levels for the income loss effects in the three regions are determined using the onlineappendix to Anthoff \& Tol (2010), which provides estimates of regional growth in income, along with expected degree of economic impact of climate change in the various regions investigated. This data were used in further calculations to arrive at plausible ranges for the income effect in year 2100 in each region, with and without the effects of further climate change (See Table 1). Respondents were informed that without further climate policy action, the average income of people living in 2100 be $5 \%$ lower, as a result of additional climate change ${ }^{6}$. We presented the effect of the climate change policies as lowering the average expected income loss across the three regions, to a varying extent $(0$, $1,2$ or $4 \%)$.

Table 1. Attributes and attribute levels

\begin{tabular}{lcc}
\hline Attributes & Levels & Status quo \\
\hline Co-benefit from regional mitigation efforts &
\end{tabular}

\section{Co-benefit from regional mitigation efforts}

\footnotetext{
${ }^{6}$ An inherent challenge is that overall income is expected to rise towards 2100 by a non-trivial amount. This means that people living now, across the three regions selected, are on average poorer than we predict people living in the same regions in 2100 to be. This could affect their choices even if they hold social preferences. In the survey, respondents were informed about this fact in the attribute-explanation section, and total per capita income for each region was displayed in each alternative in all choice sets.
} 
Fewer cases of respiratory diseases (Western Europe)

Fewer cases of respiratory diseases (Southeast Asia)

Fewer cases of respiratory diseases (Sub-Saharan Africa)

No effect

No effect

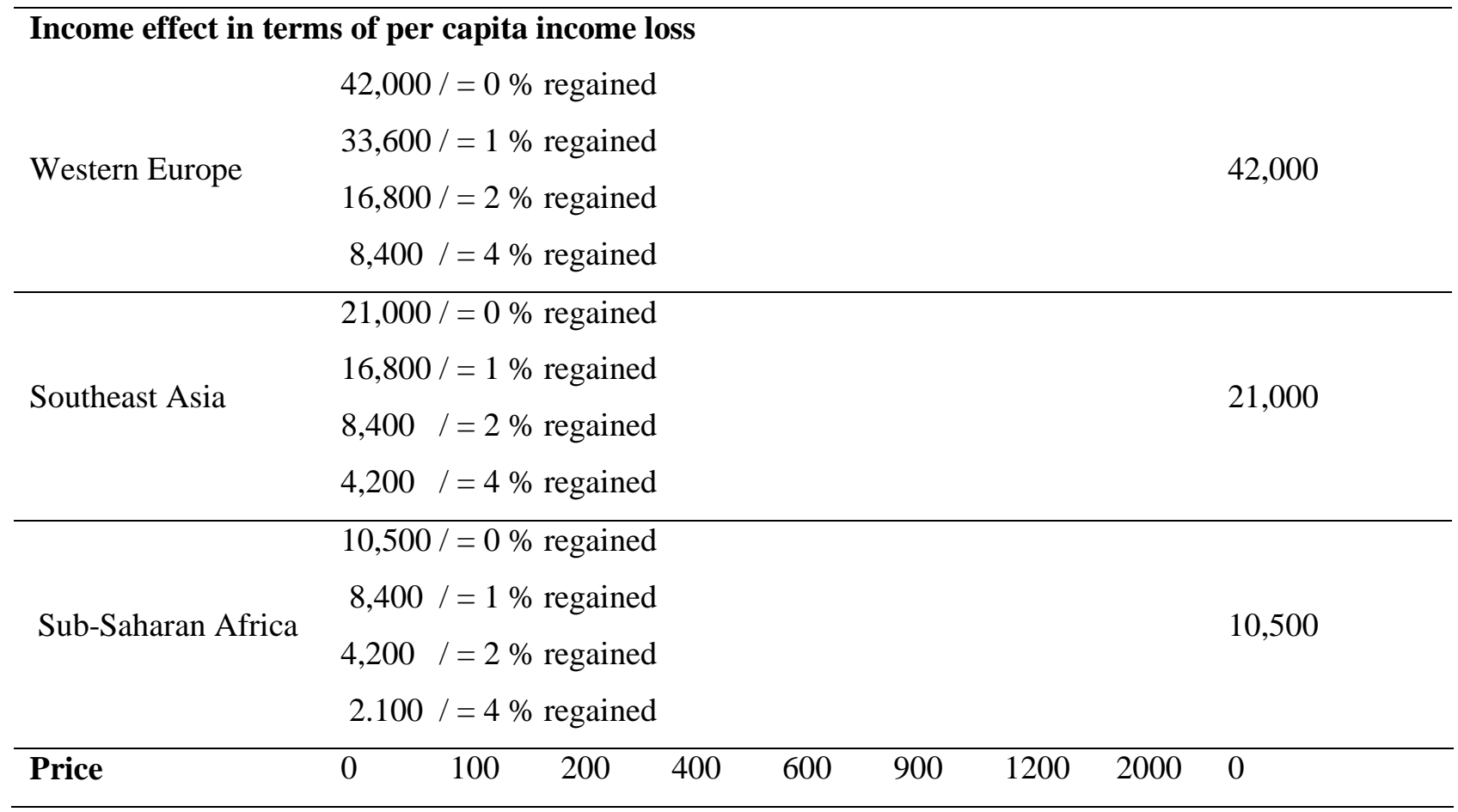

We described the mitigation effort as a set of policies targeting reduced fuel consumption through changes in combustion-technology in the energy and transportation sector, or in households. This level of detail was included in order to justify the existence of a co-benefit from the mitigation effort, which we described qualitatively as fewer cases of respiratory diseases in the region implemented (see Table 1). In the attribute description, the mitigation part of the policy could take place in only one region within each policy alternative, allowing for trade-offs across the regions with regards to this more immediate local public good.

Furthermore, we explained that adaption efforts would always be present and vary across decision alternatives and regions. We described these in general terms as varying in intensity across-and within regions, using examples such as building dikes and changed crop management.

Finally, we informed respondents that the additional climate policies would have a cost in terms of an increase in their annual household income tax (see Table 1). They were also informed that the Danish Government is committed to reducing $\mathrm{CO}_{2}$ emissions further, with national as well as international instruments, to enhance climate adaptation and support developing countries in adapting. We further informed respondents that the Danish government already contributes from the 
government budget to programs run by the EU, UN or the World Bank towards these objectives, and that these contributions could increase in the future. Lastly, respondents were informed that the results of the survey would be publicized and made available for policy makers. We believe this context enhance perceived consequentiality (Carson and Groves 2007).

The respondents faced a demanding, highly complex choice-task, spanning effects in both time and space. Therefore, we tested the survey thoroughly over the course of 6 months, with respect to understanding, wording and presentation of the case study. Testing included three focus groups and two pilot data collections, one on students and researchers with elaborate feedback and one on the panel used for the main experiment, which all provided valuable inputs to the survey design, as well as providing priors for the technical design. Two researchers were present under focus group sessions, in order to capture all relevant points, take notes and ensure sufficient flow. Discussions in focus groups tested and improved both the presentation of the co-benefit and income attributes, the latter developed to include graphics, text and numbers in order to support as many perception preferences as possible.

\subsubsection{Experimental Design}

The survey consisted of three sections. The first section contained information on the case study, along with warm-up questions on attitudes and beliefs about climate change and elements of the presented case study. In the second section, respondents were asked to make choices in 8 choice sets between three different climate policy options, of which one was always "No additional climate policy", corresponding to the status quo level of climate policy (see Figure 2 for an example of a choice card). The third and last section contained follow-up and attitude questions as well as questions eliciting socio-demographic information.

Thus, the experimental design consisted of 8 choice-tasks, each with 3 alternatives. The choice -tasks were distributed into 2 blocks, resulting in 16 different designs of the choice cards. The technical design was optimized according to D-efficiency in the program Ngene (ChoiceMetrics 2012), using a main-effects dummy-coded MNL model and the final design had a D-error of 0.3063.

Table 2. Socio-demographic characteristics of the sample and the population of Denmark

\begin{tabular}{lll}
\hline & Sample & Population of Denmark \\
& $\mathrm{n}=813$ & \\
\hline Female & 0.50 & 0.50 \\
Age & 44.90 & 41.1
\end{tabular}




$\begin{array}{lll}\text { Income }^{\mathrm{a}} & 250,000-274,999 & 261,323 \\ \text { Education - tertiary } & 0.25 & 0.12 \\ \text { Education - secondary } & 0.13 & 0.10 \\ \text { Education - vocational } & 0.52 & 0.50 \\ \text { Education - primary } & 0.09 & 0.27\end{array}$

Education levels are provided for the population aged above 15 years

a: Mean interval- income per respondent, in DKK, for the sample.

\subsection{Data collection}

The data collection was handled by means of an online panel, Userneeds, including more than 95,000 members of the general Danish public ${ }^{7}$. The survey was conducted on 813 respondents $^{8}$, in the age 18-70 years old. The average response time was approx. 20 minutes. The sampling was designed to be representative in regards to age, gender and income. From Table 2 it can be seen that the sample matched the general population very well for gender and income, but sample is on average a bit older than the general population. Furthermore, although the educational levels are similar there is an overrepresentation of respondents with a tertiary education and a symmetric underrepresentation of respondents with a primary education ${ }^{9}$.

\footnotetext{
${ }^{7}$ The members of the panel earn points when they answer a survey for the company. These points can be exchanged for gift certificates to a wide variety of non-food and food stores, as well as used to enter lotteries and as donations to good causes. For survey of the length presented in this paper, members typically earn 0.50 Euro.

${ }^{8}$ The survey included two splits, of which only one is used in this paper. Across both splits a total of 14,831 respondents were invited to the survey, of which 1,634 had completed the survey. The survey was closed once a minimum population of representative respondents had replied, thus a standard response rate cannot be estimated.

${ }^{9}$ Chi square tests indicate that the difference between age, income and educational levels of the sample and the general population is statistically significant. In section 5.5 we comment on how these differences influence our ability to generalize our results, based on auxiliary analyses that investigate how age and educational level influence model results.
} 


\begin{tabular}{|c|c|c|c|}
\hline & Climate policy 1 & Climate policy 2 & $\begin{array}{l}\text { No additional climate } \\
\text { policy }\end{array}$ \\
\hline $\begin{array}{l}\mathrm{CO}_{2} \text { reduced in: } \\
\text { Health impact in the region: }\end{array}$ & $\begin{array}{l}\text { Sub-Saharan Africa } \\
\text { Fewer cases of respiratory diseases }\end{array}$ & $\begin{array}{l}\text { Western Europe } \\
\text { Fewer cases of respiratory diseases }\end{array}$ & $\begin{array}{l}\text { No additional } \mathrm{CO} 2 \text { reduction } \\
\text { No effect }\end{array}$ \\
\hline $\begin{array}{l}\text { Western Europe - year } 2100 \\
\text { Regained income corresponds to: } \\
\text { Regained annual income } \\
\text { Annual loss - no additional climate policy }\end{array}$ & $\begin{array}{l}1 \% \text { regained out of } 840.000 \mathrm{DKK} / \text { year } \\
8.400 \\
42.000\end{array}$ & \begin{tabular}{|r|}
$4 \%$ regained out of $840.000 \mathrm{DKK} /$ year \\
33.600 \\
\end{tabular} & 42.000 \\
\hline $\begin{array}{l}\text { Southeast Asia - year } 2100 \\
\text { Regained income corresponds to: } \\
\text { Regained annual income } \\
\text { Annual loss - no additional climate policy }\end{array}$ & $\begin{array}{l}2 \% \text { regained out of } 420.000 \mathrm{DKK} / \text { year } \\
8.400 \\
\begin{array}{l}21.000 \\
\end{array}\end{array}$ & 21.000 & 21.000 \\
\hline $\begin{array}{l}\text { Sub-Saharan Africa - year } 2100 \\
\text { Regained income corresponds to: } \\
\text { Regained annual income } \\
\text { Annual loss - no additional climate policy }\end{array}$ & $0 \%$ regained out of $210.000 \mathrm{DKK} /$ year & \begin{tabular}{|l|}
$4 \%$ regained out of $210.000 \mathrm{DKK} /$ year \\
8.400 \\
10.500 \\
\end{tabular} & $\begin{array}{l}0 \% \text { regained out of } 210.000 \mathrm{DKK} / \text { year } \\
10.500\end{array}$ \\
\hline Increase in your incometax now & $1200 \mathrm{DKK}$ & $100 \mathrm{DKK}$ & 0 DKK \\
\hline
\end{tabular}

Figure 2. Example of choice card

\subsection{The Latent Class Model}

We use a latent class model to explore the possible preference heterogeneity that we a priori have formed hypotheses about. The latent class model assumes that there exists discrete heterogeneity in segments of the population, but that individuals in each class are homogenous in their preferences (Greene and Hensher 2003).

The underlying theoretical framework used to analyse the respondents' preferences is the Random Utility framework (McFadden 1973) along with Lancasters' characteristics of demand theory (Lancaster 1966). Following the Random Utility framework, the utility of agent $i$ for alternative $j$ can be described by an observable part $x_{i, j}$ and an unobservable part $\varepsilon_{i j}$, which is the individual stochastic error term. This allows the utility of agent $i$ to be formulated as follows:

$U_{i j}=\beta x_{i, j}+\varepsilon_{i j}$

Here $x_{i, j}$ may contain both individual characteristics and the characteristics of the alternatives, while $\beta$ is a vector containing parameter coefficients to be estimated. This econometric formulation directly relates to the empirical specification of the theoretical model developed in eq. (9), which forms the basis for developing the social preference hypotheses in eq. (11)-(14). 
Assuming that the error term in eq. (15) is type I extreme value distributed and that agent, $n$, chooses the alternative which gives her/him the highest utility, facing a sequence of choices, $\mathrm{T}$, and that she/he belongs to class $\mathrm{s}$, the joint probability of observing a given sequence of choices can be formulated as a multinomial logit model:

$P_{n, S}=\prod_{t}^{T}\left[\frac{\exp \left(\beta_{s} x_{n i t}\right)}{\sum_{j=1}^{J_{i}} \exp \left(\beta_{s} x_{n j t}\right)}\right], \quad s=1, \ldots, S$

Where $\beta_{s}$ is a vector of parameter estimates connected to the explanatory variables $x_{\text {nit }}$, specific for class $s$. The probability that a given individual belongs to class $\mathrm{s}$ is described by the class membership function:

$P_{n, s}=\frac{\exp \theta_{s} Z_{n}}{\sum_{s=1}^{S} \exp \theta_{s} Z_{n}} \quad, \quad s=1, \ldots \ldots, S$

Where $\theta_{s}$ is the parameter estimate connected to the observed characteristics or attitudes of individual $Z_{n}$. In estimation of (17), the parameter estimates in one of the classes is set to zero, for identification purposes.

Under the assumption of independence, the combination of the probability of a given sequence of choices given membership of class s (eq. 16), and the probability of being in class s (eq. 17), one can describe the probability of observing a sequence of choices for a random individual $n$ as:

$$
P_{n}=\sum_{S=1}^{S}\left[\frac{\exp \theta_{S} z_{n}}{\sum_{S=1}^{S} \exp \theta_{S} z_{n}}\right]\left[\frac{\exp \left(\beta_{s} x_{n i t}\right)}{\sum_{j=1}^{J_{i}} \exp \left(\beta_{S} x_{n j t}\right)}\right], \quad s=1, \ldots, S
$$

Now re-formulate (13 with respect to the empirical specification of our model from eq. (9) to yield:

$$
\begin{aligned}
& U_{i j}=\alpha A S C_{j}-\rho p_{j}+\delta_{W E} C O B_{W E, j}+\delta_{S E A} C O B_{S E A, j}+\delta_{S S A} C O B_{S S A, j}+\beta_{W E} I L_{W E, j}+ \\
& \beta_{S E A} I L_{S E A, j}+\beta_{S S A} I L_{S S A, j}+\varepsilon_{i j}
\end{aligned}
$$

Where $\alpha$ is the parameter coefficient for the alternative specific constant, $\rho$ is the parameter coefficient for the cost attribute $p_{j}$ measuring the marginal utility of income and $\varepsilon_{i j}$ represents the random error term. The remaining parameters correspond to those defined for eq. (9) above.

\section{RESULTS}

In latent class analysis it is left to the researchers' discretion to choose the number of classes, based either on theoretical arguments or guided through selection criteria such as the Bayesian Information 
Criteria (BIC) or Akaike Information Criteria (AIC). Table A0 in the Appendix shows the BIC and AIC selection criterions, as well as the log-likelihood for 1-10 classes $^{10}$.

It is natural to assume that our hypotheses may each cover a class, but also it is safe to assume they do not cover all likely preference variations (e.g. there may be people with no taste for additional climate policies). Thus, we base our choice of number of classes on the theoretical hypotheses that we wish to test for, and the information criteria and performances of different alternatives. We found that the four class model provided a reasonable fit to the observed data heterogeneity, whilst encompassing our two hypotheses, and ensuring a reasonable size of all classes. We tested the robustness of our main results to this choice and report briefly these results in Section 5.5.4

Table 3 presents the results of our preferred four class model. In Table 4 we present the corresponding WTP estimates across the four different classes and the seven attributes, including the alternative specific constant.

Before turning to the specific tests of our hypotheses, we briefly comment on the preference model and the related WTP estimates. The estimation of the latent class model was implemented using Latent Gold 5.1 (Vermunt and Magidson 2015). The log likelihood of the model is -4432 and the Rsquared 0.43 , the latter suggesting a relatively good fit of the model. We note, that with four classes, only one (Class 3 ) is fairly small encompassing only $6 \%$ of the sample. The largest, Class 1 , holds $60 \%$ of the sample and the two remaining classes each encompass $17 \%$ of the sample. We further note that the ASC is significant in all classes, but with different signs. The ASC is coded as 1 for the status quo of no additional climate policy, implying that a positive parameter reflects a preference for status quo. We also note that the price parameter is significant and negative as expected for three classes, $83 \%$ of the sample, but significant and positive for one class. We return to this finding below. Finally, we note that when income effect parameters are significant, they are negative, in accordance with the expected disutility of future income losses. Similarly, when parameters for co-benefits are significant, they are positive.

Table 3 Four Class Latent Class Model, std. errors in parenthesis

\begin{tabular}{|c|c|c|c|c|}
\hline & Class 1 & Class 2 & Class 3 & Class 4 \\
\hline Class size & 0.60 & 0.17 & 0.06 & 0.17 \\
\hline
\end{tabular}

\footnotetext{
${ }^{10}$ The different criteria do not suggest the same number as classes and furthermore, we see that the optimal number of classes, according to these criterions is rather high. This can result in classes of very small size and several insignificant parameters (Scarpa and Thiene 2005).
} 


\begin{tabular}{|c|c|c|c|c|c|c|c|c|}
\hline $\begin{array}{l}\text { Explanatory } \\
\text { variables }\end{array}$ & Coef & $\mathrm{z}$ & Coef & $\mathrm{z}$ & Coef & $\mathrm{z}$ & Coef & $\mathrm{z}$ \\
\hline \multirow[t]{2}{*}{$\overline{\mathrm{ASC}}$} & -3.397 & 8.769 & -0.893 & 4.819 & 2.780 & 3.339 & -0.981 & 2.270 \\
\hline & $(0.387)$ & & $(0.185)$ & & $(0.833)$ & & $(0.432)$ & \\
\hline \multirow[t]{2}{*}{ Income effect: $W E$} & -0.029 & 11.210 & -0.006 & 1.344 & 0.026 & 0.672 & -0.039 & 5.254 \\
\hline & $(0.003)$ & & $(0.005)$ & & $(0.039)$ & & $(0.007)$ & \\
\hline \multirow[t]{2}{*}{ Income effect: $S E A$} & -0.021 & 5.287 & -0.015 & 1.778 & 0.048 & 1.060 & -0.016 & 1.431 \\
\hline & $(0.004)$ & & $(0.008)$ & & $(0.045)$ & & $(0.011)$ & \\
\hline \multirow[t]{2}{*}{ Income effect: $S S A$} & -0.077 & 9.555 & 0.001 & 0.054 & 0.015 & 0.171 & 0.026 & 1.033 \\
\hline & $(0.008)$ & & $(0.017)$ & & $(0.087)$ & & $(0.025)$ & \\
\hline \multirow[t]{2}{*}{ Co-benefit: $W E$} & 1.768 & 16.533 & 0.552 & 3.278 & 0.312 & 0.364 & 0.758 & 3.238 \\
\hline & $(0.107)$ & & $(0.168)$ & & $(0.859)$ & & $(0.234)$ & \\
\hline \multirow[t]{2}{*}{ Co-benefit: $S E A$} & 1.025 & 13.542 & -0.023 & 0.161 & -1.316 & 1.188 & 0.522 & 2.829 \\
\hline & $(0.076)$ & & $(0.145)$ & & $(1.108)$ & & $(0.185)$ & \\
\hline \multirow[t]{2}{*}{ Co-benefit: $S S A$} & 1.173 & 12.311 & -0.011 & 0.062 & -0.226 & 0.024 & -0.076 & 0.308 \\
\hline & $(0.095)$ & & $(0.168)$ & & $(0.925)$ & & $(0.246)$ & \\
\hline \multirow[t]{2}{*}{ Price } & -0.545 & 7.993 & -2.046 & 10.564 & -0.128 & 0.230 & 1.508 & 6.548 \\
\hline & $(0.068)$ & & $(0.194)$ & & $(0.554)$ & & $(0.230)$ & \\
\hline \multicolumn{9}{|l|}{ Model Statistics } \\
\hline No. of respondents & 813 & & & & & & & \\
\hline Choices/person & 8 & & & & & & & \\
\hline LL & -4432 & & & & & & & \\
\hline BIC & 9099 & & & & & & & \\
\hline$R$-squared & 0.432 & & & & & & & \\
\hline
\end{tabular}

Table 4 Willingness to pay estimates (DKK for significant coefficients in the main model (Table 3)

\begin{tabular}{|c|c|c|c|c|c|}
\hline & Class1 & & Class2 & Class3 & Class4 \\
\hline \multirow[t]{2}{*}{$\mathrm{ASC}$} & $-6,236$ & $* * *$ & $-0,436 * * *$ & $21,811 *$ & 0,651 \\
\hline & $(1,030)$ & & $(0,101)$ & $(9,632)$ & $(0,348)$ \\
\hline \multirow[t]{2}{*}{ Income effect: $W E$} & $-0,053$ & $* * *$ & $-0,003$ & 0,207 & $0,026 * * *$ \\
\hline & $(0,008)$ & & $(0,002)$ & $(1,062)$ & $(0,005)$ \\
\hline \multirow[t]{2}{*}{ Income effect: $S E A$} & $-0,039$ & $* * *$ & $-0,007$ & 0,377 & 0,011 \\
\hline & $(0,009)$ & & $(0,004)$ & $(1,671)$ & $(0,008)$ \\
\hline \multirow[t]{2}{*}{ Income effect: $S S A$} & $-0,142$ & $* * *$ & 0,000 & 0,117 & $-0,017$ \\
\hline & $(0,019)$ & & $(0,008)$ & $(0,834)$ & $(0,016)$ \\
\hline
\end{tabular}




\begin{tabular}{lcccc} 
Co-benefit: $W E$ & $3,245 * * *$ & $0,270 * * *$ & 2,450 & $-0,503 * *$ \\
& $(0,340)$ & $(0,080)$ & $(9,671)$ & $(0,175)$ \\
Co-benefit: $S E A$ & $1,882 * * *$ & $-0,011$ & 4,218 & $-0,346 *$ \\
& $(0,240)$ & $(0,071)$ & $(4,667)$ & $(0,140)$ \\
Co-benefit: $S S A$ & $2,153 * * *$ & 0,005 & $-1,773$ & 0,050 \\
& $(0,259)$ & $(0,082)$ & $(1,255)$ & $(0,160)$ \\
\hline Note: Std. Error in parenthesis. Significance levels: * $0.05, * * 0.01, * * * 0.001$ &
\end{tabular}

Turning to the WTP-estimates in Table 4, we see that respondents belonging to Class 1 express significant WTP for all parameters and are e.g. willing to pay 0,142 DKK yearly to avoid the future loss of 1 DKK for households in year 2100 in South Saharan Africa (SSA). Respondents in Class 2 reveal a willingness to support a change from the status quo (negative ASC), but likely driven by the WTP for co-benefit in their own region - otherwise we find no significant WTP. Class 3 has a positive WTP for not implementing further policies, i.e. the status quo. For Class 4 , the WTP measures cannot be interpreted meaningfully, due to the positive preference parameter for parting with income, and we discuss this below where for each class, we evaluate the tests of our hypotheses.

Our hypotheses concerning 'Inequity Averse Altruist'-preferences regarding income effects are specified in eq. (11), and regarding co-benefits in eq. (12). The corresponding hypotheses for 'Altruist'-preferences are specified in eq. (13)-(14). We test these both using the preference parameters (Table 5) and in the WTP estimates (Table 6)

Table 5

Wald test of equality of regression coefficients

\begin{tabular}{rllll}
\hline & Class 1 & Class 2 & Class 3 & Class 4 \\
\hline Income effects & & & & \\
WE = SEA & 1.40 & 0.94 & 0.34 & -1.74 \\
WE = SSA & $5.52^{* * *}$ & 0.42 & 0.13 & $-2.48^{*}$ \\
SEA = SSA & $6.54^{* * *}$ & 0.91 & 0.32 & -1.61 \\
\hline Co-benefits & & & & 1.01 \\
WE = SEA & $8.42^{* * *}$ & $3.53^{* *}$ & 1.45 & $3.30^{* *}$ \\
WE $=$ SSA & $8.12^{* * *}$ & $3.19^{* *}$ & 0.65 & $2.97^{* *}$ \\
\hline SEA $=$ SSA & 1.90 & 0.22 & 0.91 &
\end{tabular}

Note: Significance levels: $* 0.05, * * 0.01, * * * 0.001$ 


\begin{tabular}{rllll}
\hline & Class 1 & Class 2 & Class 3 & Class 4 \\
\hline Income effects & & & & \\
WTP $_{\mathrm{WE}}=\mathrm{WTP}_{\mathrm{SEA}}$ & 1.18 & 0.94 & -0.09 & 1.61 \\
$\mathrm{WTP}_{\mathrm{WE}}=\mathrm{WTP}_{\mathrm{SSA}}$ & $4.24 * * *$ & 0.41 & 0.07 & $2.50^{*}$ \\
$\mathrm{WTP}_{\mathrm{SEA}}=\mathrm{WTP}_{\mathrm{SSA}}$ & $4.83^{* * *}$ & 0.85 & 0.14 & 1.54 \\
\hline Co-benefits & & & & \\
$\mathrm{WTP}_{\mathrm{WE}}=\mathrm{WTP}_{\mathrm{SEA}}$ & $3.27^{* *}$ & $2.62^{* *}$ & -0.16 & 0.70 \\
$\mathrm{WTP}_{\mathrm{WE}}=\mathrm{WTP}_{\mathrm{SSA}}$ & $2.55^{*}$ & $2.30^{*}$ & 0.43 & $2.33^{*}$ \\
$\mathrm{WTP}_{\mathrm{SEA}}=\mathrm{WTP}_{\mathrm{SSA}}$ & 0.77 & 0.15 & 1.24 & 1.87 \\
\hline
\end{tabular}

Note: Significance levels: $* 0.05, * * 0.01, * * * 0.001$

\subsection{Hypotheses testing in Class 1}

Considering the coefficient equality tests in Table 5 and the WTP equality tests in Table 6 , we note they are similar with a slight loss in power for WTP caused by the variance-covariance of the parameters in the composite measures.

Class 1 contains $60 \%$ of the sample. Consider the tests for the income effect estimates in light of the hypothesis of Inequity Averse Altruists (eq. 11) or Altruism as defined in eq. (13). For WE and SEA, we cannot reject equality, although estimates for WE are somewhat higher than for SEA. Equality of estimates is soundly rejected for both WE vs SSA and SEA vs SSA. As discussed earlier, respondents may hold bequest values for their own off-spring and families. They may also have a self-interest in WE income effects due to the potential experiencing the beginning of income effects within their own lifetime. Indeed a sensitivity analysis, cf. section 5.5.5, showed that the younger the respondent, the higher the WTP for avoiding WE income losses. The results can be interpreted as these self-interests are large enough to outweigh respondents' inequity aversion with regard to WE vs SEA, but not for WE vs SSA. If we accept this reasoning, results suggest that we cannot reject the hypothesis that Class 1 respondents showed some degree of Inequity Averse Altruists with regard to the future income effects (at least for other regions and somewhat blurred by self-interest in WE outcomes), but likely can reject that they are simply Altruists with regard to future income effects, cf. eq. 13. Turning to co-benefits, we find that we can reject the hypothesis of equality of estimates for WE vs SEA and WE vs SSA, with the WE estimates being significantly larger, but we cannot reject the hypothesis for SEA vs SSA. As the co-benefit affects current generations, self-interest on behalf of 
the respondent is to be expected, and thus these results suggest that we can reject the hypothesis of Class 1 respondents being Inequity Averse Altruists with respect to co-benefits (see eq. (12)). However, we cannot reject the hypothesis of respondents being Altruist (eq. (14)) with respect to cobenefits (at least for other regions and somewhat blurred by self-interest in WE outcomes).

\subsection{Hypothesis testing for Class 2}

This class includes $17 \%$ of the sample. In Class 2, the coefficients on the income effects in the three regions (WE, SEA \& SSA) are all statistically insignificant, and none of the tests of equality of parameters or WTP can be rejected. This implies that we soundly reject the hypothesis of Inequity Averse Altruists (eq. (11)) with regard to future income effects of climate policies. However, as the coefficients and WTP measures are insignificant, we also have to reject the hypothesis of Altruist for future income effects (eq. (13)).

Turning to co-benefits, we find that respondents only care for the co-benefit outcome in WE, as parameters and WTP are insignificant for SEA and SSA. As a result tests for equality are rejected for the tests involving WE, with WE being significantly larger. We thus reject the hypotheses of Class 2 respondents being Inequity Averse Altruists or Altruists with respect to co-benefits (see eq. (12) and (14)).

We not that the WTP for the ASC is negative and significant, indicating that respondents captured by this class had a positive utility gain from just choosing a climate policy (regardless of co-benefits or other outcomes) as opposed to the status quo. Note, however, that it is small compared to Class 1. This effect could reflect a small "warm glow" from the mere act of choosing and indicating a positive WTP for additional climate policy (Andreoni 1990)

\subsection{Hypothesis testing for Class 3}

This class captures $6 \%$ of the respondents. In Class 3 only the coefficient on and WTP for the ASC is statistically significant and positive, and thus we interpret this class as capturing respondents with an affinity for the status quo. These are respondents who did not want to invest in additional climate policy. With these parameters, we have to reject both the hypothesis of Inequity Averse Altruists and Altruists with regard to both future income effects and co-benefit outcomes.

\subsection{Hypothesis testing for Class 4}

This class captures approximately $17 \%$ of the respondents. Considering the preferences regarding future income effects only the coefficient for income effects in WE is significant, implying that only 
future losses in income in their own region significantly impact respondent utility. For this reason the hypothesis of Inequity Averse Altruists as well as Altruists with regard to future income effects must be rejected (see eq. (11) and (13)). Turning to the co-benefits we find statistically significant preference parameters in two regions, WE and SEA. A test of equality of preference parameters for WE vs SEA cannot be rejected, which leaves us to conclude that the results appear inconclusive with respect to Altruist preferences (eq. (14)).

The price coefficient for Class 4 was found positive and significant (see Table 3). This is not what is expected from theory (which predicts a negative parameter and hence positive marginal utility of income), but the result appeared consistently across numerous model versions. The result makes the WTP estimates of Table 4 questionable, and hence we rely only on the preference model tests here (Table 3 and 5). We will discuss this pattern in more detail in Section 6. However, while this group is hard to interpret, we have to maintain the conclusion that its behaviour does not align with either of our theoretical models of social preferences over climate policy outcomes.

\subsection{Robustness of specification}

To evaluate the robustness of our main findings from the model above, we investigated several different specifications of our model. Table 7 shows a summary of the robustness checks we have performed and below we focus our treatment on the first and second robustness check, while the remaining checks are only briefly described ${ }^{11}$.

\begin{tabular}{|c|c|c|c|c|c|c|}
\hline & A class & & Majority is & & & \\
\hline Robustness check & $\begin{array}{l}\text { Inequity } \\
\text { Averse in } \\
\text { income }\end{array}$ & $\begin{array}{l}\text { No class is } \\
\text { Altruists in } \\
\text { income }\end{array}$ & $\begin{array}{l}\text { Inequity } \\
\text { Averse in } \\
\text { income }\end{array}$ & $\begin{array}{l}\text { A class } \\
\text { focused on } \\
\text { WE only }\end{array}$ & $\begin{array}{l}\text { A class with } \\
\text { only status quo } \\
\text { preference }\end{array}$ & $\begin{array}{l}\text { A class with } \\
\text { positive price } \\
\text { parameter }\end{array}$ \\
\hline \multicolumn{7}{|l|}{$\begin{array}{l}\text { LC model with } \\
\text { class membership } \\
\text { function }\end{array}$} \\
\hline $\begin{array}{l}\text { Subsample of } \\
\text { data }\end{array}$ & & & & & & \\
\hline
\end{tabular}

\footnotetext{
11 The Appendix contains regression tables for the most informative robustness checks.

12 The conclusions with respect to Inequity Aversion with respect to future income effects being the largest class in the data also hold when testing models with 1-5 classes.
} 


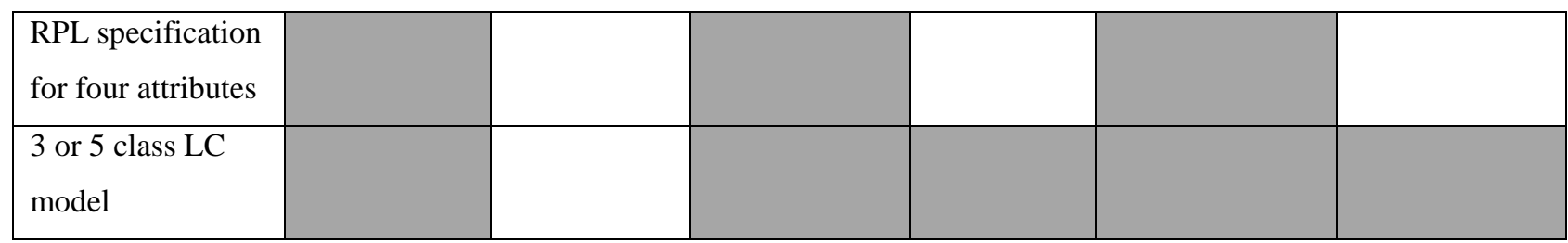

Note: The grey-shaded areas mark that the finding was present for the model variant. For the "3 or 5 class LC model" check, the box indicating that a class with a positive price parameter refer only to the 5 class LC model.

\subsubsection{Latent Class model with class membership function}

The survey contained a battery of follow-up questions and embedded in this battery were questions designed to capture attitudes that might be related to the hypothesized preference types of Inequity Averse Altruists and Altruists, but also other behavioural aspects e.g. related to bequest values, concerns for effects on own life time income and warm glow donation motives. The questions can be seen in Table 8 below $^{13}$. We note that it can be argued that there is a risk of a technical endogeneity between the respondents' answers to attitude questions and their choices in choice sets, as both could be influenced by an unobserved latent type (Hess, Shires et al. 2013). This should be in mind when interpreting results. Table A2 in the Appendix presents the results of this specification. Overall the LL improves from -4432 (model with no class membership function) to -4366 (model with class membership function), a significant drop in likelihood units (Likelihood Ratio test, chi-square value $=133.35, \mathrm{df}=15)$.

Table 8 Attitude questions used as variables in the class membership function

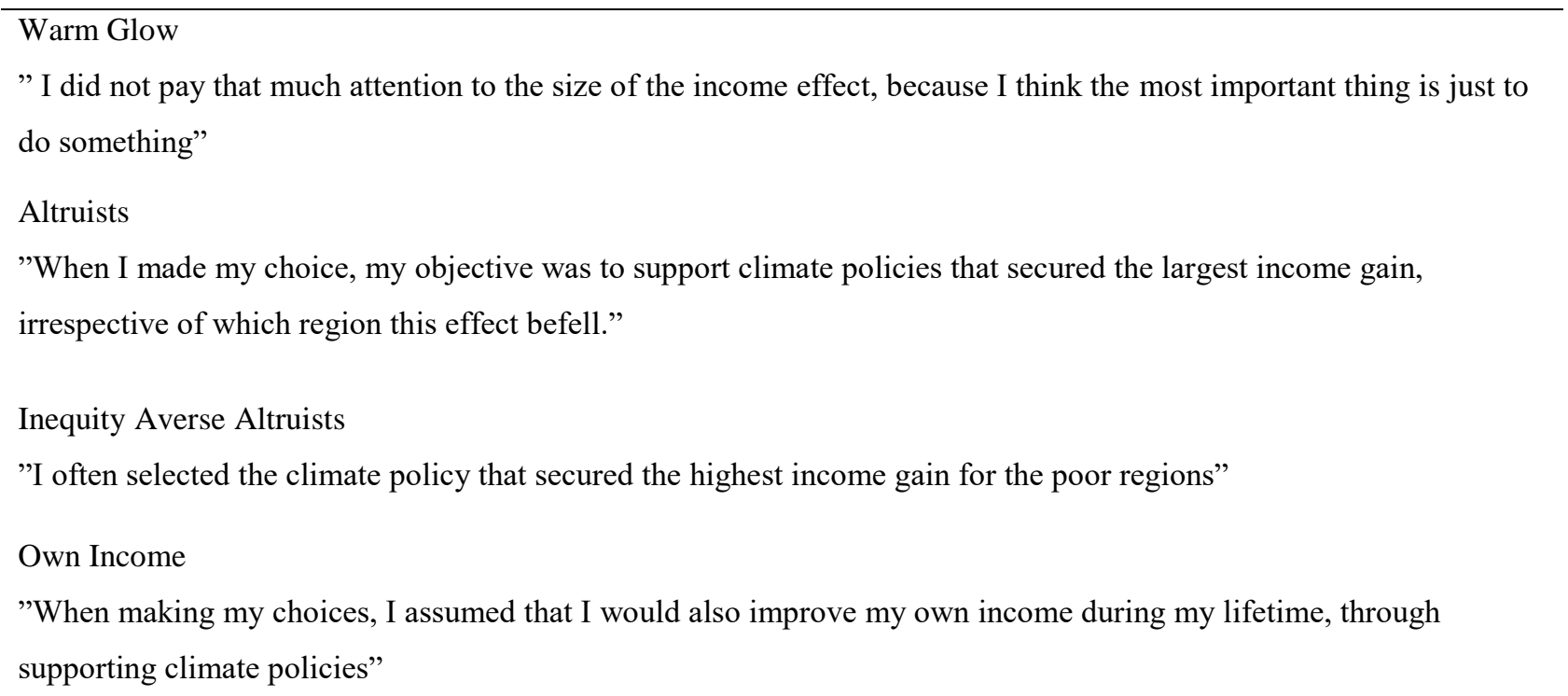

\footnotetext{
${ }^{13}$ The descriptive statistics for each attitude question can be found in A1 in the Appendix
} 


\section{Bequest Value}

"I made my choices thinking about my (future) grandchildren"

Importantly, we find that the estimated attribute parameters and class sizes are almost identical to the model presented in Table 3. The largest class is once more comprised of respondents that display Inequity Averse Altruist preferences with regard to effects on future income.

The respondents assigned to the first class (59\%) and the fourth class $(18 \%)$, resembling the first and fourth class in our main model, were more likely to agree with the Inequity Averse Altruists

and Altruist statements, than respondents belonging to the second and third classes. The fourth class, still having a positive price parameter, was furthermore more likely to agree with Bequest and Warm Glow type statements, cf. Table 8, but significantly less likely than respondents in the first and second class to declare a focus on effects of climate policy for their own income. Thus, the fourth class appeared to state many different justifications for their choices. The second class again only had a significant parameter for local co-benefits. This class was more likely to agree with the statement about concerns for own income than was respondents in class one, but less likely to agree with statements on warm glow and inequity aversion. Respondents in the third class remained uninterested in any climate policy attributes, and were less likely to agree with any statements, than the other groups.

\subsubsection{Subsample of data}

The choice task was arguably complex for respondents and one could suspect that perhaps some respondents were not able to read the choice card in the intended way. In an attempt to evaluate this concern, we included a follow-up question aimed at measuring whether or not a respondent was able to read a complex choice card correctly ${ }^{14}$, and $63 \%$ provided the correct answer to the question. Table in the Appendix presents the results of a latent class model with four classes, based on this subsample of data. The results indicate that the largest class of respondents display Inequity Averse Altruist preferences with respect to future income effects (58\%). Apart from this main finding a second class had significant preferences for avoiding income losses in two regions, including WE. Finally, we again find a group of respondents who display a positive price parameter, with an apparent preference for income and co-benefit effects in WE. Thus, the main finding of this robustness check is that the

\footnotetext{
${ }^{14}$ The question showed the same type of choice card that respondents had just answered, and asked the following question: "Which of the climate policies secures the largest gain in income in Sub-Saharan Africa".
} 
conclusions from the main model with respect to a majority of the respondents being Inequity Averse Altruists for future income effects and Altruists in relation to co-benefits hold for this subsample of respondents.

\subsubsection{Random preference heterogeneity: An LC-model with RPL specification for four attributes}

There are many ways of allowing for preference heterogeneity. We explored a latent class model with random parameters for the co-benefits and price attributes, thus fixing their means across the four classes, but allowing for taste heterogeneity across the sample being captured in a normal distribution around the mean. This implies that only preferences for the income effect attributes, and hence the hypotheses in eq. (11) and eq. (12), are evaluated at class level.

Table A4 in the Appendix presents the results of such a model. The LL significantly improves from -4432 to -4389 (Likelihood Ratio test, chi-square value $=85.09, \mathrm{df}=8$ ). The coefficients on price is negative and significant, but the large taste variation captured in the standard deviation estimated hints at the presence of respondents with little or even positive price parameters.

The estimate for the co-benefits are all significant, and align with pattern of Class 1 in our main results, i.e. the preference is strongest for WE co-benefits, and otherwise aligned with the Altruist hypothesis. For the income effect preferences, we also find our main results confirmed. Two classes now hold preferences that align with the hypothesis of Inequity Averse Altruists for income effects, modified by additional preferences for WE income effects.

\subsubsection{Alternative class numbers}

We investigated the effect of varying the number of estimated classes. The strength of the latent class model is that it allows for discrete preference heterogeneity, but the behavioural traits identified may depend on the number of estimated classes. We found, however, that estimating a latent class model with 3 or 5 classes did not alter the results that a majority of respondents display preferences consistent with Inequity Averse Altruists with respect to future income effects.

\subsubsection{Systematic preference heterogeneity}

The preferences for climate policy might vary systematically with socio-demographic characteristics of the respondents, such as the age and attained educational level. Interacting these demographics in the LC models resulted in too many insignificant parameters for interpretation to be meaningful. Therefore, we decided to evaluate the effects of age and educational level in a simple MNL. We found that in a MNL model, the pattern across the climate policy attributes are much like the ones found for 
Class 1 in our main model ${ }^{15}$. Interacting age as a continuous variable on income effects and cobenefits, we find that the older a person, the less weight they assign to income effects in WE. This could reflect less concern about e.g. effects in own life time/own life income. However, the effect is small (two magnitudes below main effects) and with the small deviation in average age between our sample and the population (2-3 years), this small effect is unlikely to distort the overall conclusion. It does indicate, however, that concerns about effects in the respondents own lifetime could be one motivation for the $|\mathrm{WE}|>|\mathrm{SEA}|$ difference observed in our main model, which outweigh the inequity aversion at aggregate sample level. Furthermore, as our sample is slightly older than the population, our estimates of this effect may be on the conservative side relative to the population, though the effect on preferences per age year in absolute terms is small.

Regarding the influence of the respondents educational level, we investigated the effect of only having obtained a primary education. We find that people with a primary education as their highest education level are less willing to pay for the co-benefit effects, no matter the region. However, overall preference patterns and results prevail. In conclusion, the results from investigating systematic preference heterogeneity do indicate that the preference for both future income effects and the generation of present-time co-benefits, are related to the age and educational level of the sampled respondents. The overrepresentation of older respondents in our sample is thus likely to underestimate the preference for future income effects in the respondents own region, while the underrepresentation of respondents with a primary education is likely to overestimate the effect of co-benefits.

\section{CONCLUDING DISCUSSION}

This paper presents empirical results that support the inclusion of distributional social preferences when designing and evaluating climate policy. Including such distributional concerns has important and significant impacts on the design and evaluation of such policies (Anthoff and Tol 2010).

We formulated two distinct social preference hypotheses regarding preferences for the distributional impacts of income effects for future generations and co-benefit effects for current generations. We found that for a prominent and stable class in our sample, capturing around $60 \%$, we could not reject the hypothesis that they held Inequity Averse Altruists preferences with regard to income effects for future generations, and held Altruist preferences with regard to co-benefit effects for current generations. For both outcomes, respondents displayed a preference for supporting better outcomes

\footnotetext{
${ }^{15}$ Models are available from the authors upon request.
} 
in their own region (WE). Subjecting this finding to several robustness checks does not alter the overall conclusion that the behavioural pattern of Inequity Averse Altruists with regard to future income effects is relevant for describing a significant part of our respondents' choice of climate policy.

We were not able to find patterns of behaviour that were consistent with the hypothesis of Altruist preference with regard to future income effect, however Inequity Averse preferences did not appear relevant with regard to the health benefits related to the co-benefit variable.

The remaining classes either showed little interest in additional climate policy or mainly revealed preferences over outcomes in their own region.

Our sample is slightly older than the Danish population and also deviates somewhat in educational level; in particular it contains fewer people with only a primary school education. We evaluated the possible effects of these deviations, and found that while preferences do vary systematically with these variables, the effect is so small that it likely not alters the main conclusion despite some deviations in sociodemographic distribution between our sample and the general population of Denmark.

We thus find convincing indications that distributional preferences are relevant in describing the choice of climate policy, for a non-trivial share of a sample of the Danish population. Specifically, the majority of respondents in our sample prefer climate policies to target lower future income impacts from climate change, for people who are less well off.

We found a clear tendency for respondents to prefer to secure co-benefits in their own region, Western Europe. This suggests a locational preference, a "yes-in.my-backyard" effect which also has been found previously in the literature (Carlsson, Kataria et al. 2012, Longo, Hoyos et al. 2012, Torres, MacMillan et al. 2015, Buntaine and Prather 2017) ${ }^{16}$. One could argue that attempting to confirm social preferences from both period 1 and 2 utility using the same set of assumptions is challenging, since the two periods are not entirely comparable. In period 1, the agent making the choice to allocate money to climate policy stands to gain a co-benefit himself, whereas the other component of climate policy, the future income losses, is not directly relevant for the agent making the choice now, since he/she will not be alive to experience this effect. So in the context of social preferences in period 2, social preferences are (mainly) expressed on behalf of other, future individuals, whereas social

\footnotetext{
${ }^{16}$ However, other studies have found a reversed or no effect of the locational preference for receiving the benefits of mitigation in the participants own region (Baranzini, Borzykowski et al. 2016, Diederich and Goeschl 2017).
} 
preferences in period 1 contain a clearer component of self-interest and self-involvement since the social preferences span a context where the decision-maker her/himself can gain something. It is therefore perhaps not too surprising that we find a clear tendency for respondents to favour co-benefits in the respondents' own region, Western Europe.

The reduced, strict social preferences typology introduced and tested is of course a subset of many possible social preferences relating to distributive impacts of climate change. Furthermore, it is also plausible that different social preferences might co-exist, and that people possess several different forms of social preferences in a given context, which we are not able to capture in our experimental design.

Another caveat is the complex context and hypothetical nature of the study and although great efforts were made to simplify and reduce the presentation, we cannot exclude that this might influence the behavioral patterns in our data. Indeed the proportion of respondents who appeared to have difficulties interpreting the choice sets was not negligible. While excluding these does not affect overall findings, it is not possible to say conclusively if their expression of preferences would be affected by a better understanding of the context and choices.

Our findings rely on a hypothetical stated preference technique, which limits the degree to which we can say that preferences are robust enough to carry over into the corresponding non-hypothetical context. Such a context is not easily produced, though, as policy motions affecting household taxes are never voted about directly in Denmark. Thus, any revealed preference attempts will have to pick a different and likely less attractive payment vehicle, e.g. donation.

Additional attention is needed for Class 4 (about $17 \%$ ), which we found to have a positive preference parameter for costs. This corresponds to a positive utility effect of parting with money - at least in the context of the questionnaire. We note that the presence of this class appeared fairly persistent across model variations. It is not uncommon in stated preference studies to find groups with very small and even insignificant cost parameters (Hess et al. 2013), which could suggest nonattendance to cost. However, Hess et al (2013) documents that nonattendance to crucial parameters is likely less common than often believed, and that taste heterogeneity is likely the better hypothesis. With the clear positive parameter found in Class 4, nonattendance seems to us not a likely explanation. We instead speculate, but cannot verify, that the identified preference pattern of this class could be caused by respondents signalling a general willingness to support climate policy by picking the more expensive choices, but not caring much for the attributes otherwise. 
Finally, our sample is only composed of Danish individuals and we cannot know whether the preference patterns we identify are descriptive for other nationalities too. This of course is an important question to consider for the results to be broadly relevant for policy assessments. On that note it could be especially interesting to sample several different nationalities to investigate the possible differences in the valuation of distributional impacts from climate policy. Secondly, before such a practice is instigated, more work on the actual metric used to weigh distributional concerns is needed, since our study also indicated that these distributional concerns are likely to be heterogeneous in nature.

Acknowledging the above limitations of the study, the policy relevance of our study is obvious. We find empirical support for the hypothesis that people, in our case Danes, care about and express preferences concerning the distributional impacts of climate policies affecting future generations in regions of disparate wealth. While limited to Danes, we expect that future studies inspired by this may confirm similar preference structures in other nations and countries.

The results thus lend empirical and context specific support to the practice of including equity weights or related adjustments for distributional impact of policies in the literature and research on climate policy design and evaluation. As this literature documents (Fankhauser, Tol et al. 1997, Pearce 2003, Johansson-Stenman 2005, Anthoff, Hepburn et al. 2009; Anthoff and Tol 2010) the policy consequences of this practice, relative to ignoring distributional impacts, are signficant notably in the developed world. 


\section{REFERENCES}

Alló, M. and M. L. Loureiro (2014). "The role of social norms on preferences towards climate change policies: A meta-analysis." Energy Policy 73(0): 563-574.

Andreoni, J. (1990). "Impure Altruism and Donations to Public Goods: A Theory of WarmGlow Giving." The Economic Journal 100(401): 464-477.

Andreoni, J. and W. T. Harbaugh (2007). Altruism in Experiments.

Anthoff, D., et al. (2009). "Equity weighting and the marginal damage costs of climate change." Ecological Economics 68(3): 836-849.

Anthoff, D. and R. S. J. Tol (2010). "On international equity weights and national decision making on climate change." \ournal of Environmental Economics and Management 60(1): 1420 .

Baranzini, A., et al. (2016). Carbon offsets out of the woods? The acceptability of domestic vs. international reforestation programmes. London: Grantham Research Institute on Climate Change and the Environment. Working paper No.257.

Bardsley, N. and R. Sugden (2006). Human Nature and Sociality in Economics. Handbook of the Economics of Giving, Altruism and Reciprocity. S. C. Kolm and J. M. Ythier, North-Holland. 1: 731-765.

Beck, M. J., et al. (2013). "Environmental attitudes and emissions charging: An example of policy implications for vehicle choice." Transportation Research Part A: Policy and Practice 50(0): 171-182.

Berk, R. and R. Fovell (1999). "Public Perceptions of Climate Change: A 'Willingness to Pay' Assessment." Climatic Change 41(3-4): 413-446.

Buntaine, M. T. and L. Prather (2017). Global Problems, Local Solutions: Preferences for Domestic Action Over International Transfers in Global Climate Policy, University of California.

Burlando, R. M. and F. Guala (2005). "Heterogeneous Agents in Public Goods Experiments." Experimental Economics 8(1): 35-54. 
Cai, B., et al. (2010). "Distributional Preferences and the Incidence of Costs and Benefits in Climate Change Policy." Environmental and Resource Economics 46(4): 429-458.

Cappelen, A. W., et al. (2007). "The Pluralism of Fairness Ideals: An Experimental Approach." American Economic Review 97(3): 818-827.

Carlsson, F., et al. (2012). "Paying for Mitigation: A Multiple Country Study." Land Economics 88(2): 326-340.

Carson, R. T. and T. Groves (2007). "Incentive and informational properties of preference questions." Environmental and Resource Economics 37(1): 181-210.

ChoiceMetrics (2012). Ngene 1.1.1 User Manual \& Reference Guide. Australia.

Clément, V., et al. (2015). "Perceptions on equity and responsibility in coastal zone policies." Ecological Economics 119: 284-291.

Dannenberg, A., et al. (2010). "Do Equity Preferences Matter for Climate Negotiators? An Experimental Investigation." Environmental and Resource Economics 47(1): 91-109.

Diederich, J. and T. Goeschl (2014). "Willingness to Pay for Voluntary Climate Action and Its Determinants: Field-Experimental Evidence." Environmental and Resource Economics 57(3): 405-429.

Diederich, J. and T. Goeschl (2017). Does Mitigation Begin At Home? Discussion Paper Series No. 634, University of Heidelberg.

Engelmann, D. and M. Strobel (2004). "Inequality aversion, efficiency, and maximin preferences in simple distribution experiments." American Economic Review: 857-869.

Fankhauser, S., et al. (1997). "The Aggregation of Climate Change Damages: a Welfare Theoretic Approach." Environmental and Resource Economics 10(3): 249-266.

Fehr, E. and K. M. Schmidt (1999). "A Theory of Fairness, Competition, and Cooperation." The Quarterly Journal of Economics 114(3): 817-868. 
Fehr, E. and K. M. Schmidt (2006). The Economics of Fairness, Reciprocity and Altruism Experimental Evidence and New Theories. Handbook of the Economics of Giving, Altruism and Reciprocity. S. C. Kolm and J. M. Ythier, North-Holland. 1: 615-684.

Fischbacher, U. and S. Gachter (2010). "Social Preferences, Beliefs, and the Dynamics of Free Riding in Public Goods Experiments." American Economic Review 100(1): 541-556.

Greene, W. H. and D. A. Hensher (2003). "A latent class model for discrete choice analysis: contrasts with mixed logit." Transportation Research Part B: Methodological 37(8): 681-698.

Grubb, M. (1995). "Seeking Fair Weather: Ethics and the International Debate on Climate Change." International Affairs (Royal Institute of International Affairs 1944-) 71(3): 463-496.

Hess, S., et al. (2013). "Accommodating underlying pro-environmental attitudes in a rail travel context: Application of a latent variable latent class specification." Transportation Research Part D: Transport and Environment 25: 42-48.

Ikeme, J. (2003). "Equity, environmental justice and sustainability: incomplete approaches in climate change politics." Global Environmental Change 13(3): 195-206.

IPCC (2014). Climate Change 2014: Synthesis Report. Contribution of Working Groups I, II and III to the Fifth Assessment Report of the Intergovernmental Panel on Climate Change R. K. P. a. L. A. Meyer. Geneva, Switzerland, IPCC: 151 pp.

Johansson-Stenman, O. (2005). "Distributional Weights in Cost-Benefit Analysis: Should We Forget about Them?" Land Economics 81(3): 337-352.

Johnson, E. and G. F. Nemet (2010). WIllingness to pay for climate policy: a review of estimates. Working Paper Series, La Follette School

Konow, J. (2001). "Fair and square: the four sides of distributive justice." Journal of Economic Behavior \& Organization 46(2): 137-164.

Kverndokk, S., et al. (2014). "The trade-off between intra- and intergenerational equity in climate policy." European Economic Review 69(0): 40-58.

Lancaster, K. J. (1966). "A New Approach to Consumer Theory." Џournal of Political Economy 74(2): 132-157. 
Lange, A., et al. (2007). "On the importance of equity in international climate policy: An empirical analysis." Energy Economics 29(3): 545-562.

Layton, D. F. and G. Brown (2000). "Heterogeneous Preferences Regarding Global Climate Change." Review of Economics and Statistics 82(4): 616-624.

Longo, A., et al. (2012). "Willingness to Pay for Ancillary Benefits of Climate Change Mitigation." Environmental and Resource Economics 51(1): 119-140.

MacKerron, G. J., et al. (2009). "Willingness to pay for carbon offset certification and cobenefits among (high-)flying young adults in the UK." Energy Policy 37(4): 1372-1381.

McFadden, D. (1973). Conditional logit analysis of qualitative choice behaviour. New York, Academic Press.

Pearce, D. (2003). "The Social Cost of Carbon and its Policy Implications." Oxford Review of Economic Policy 19(3): 362-384.

Rodríguez-Entrena, M., et al. (2014). "The role of ancillary benefits on the value of agricultural soils carbon sequestration programmes: Evidence from a latent class approach to Andalusian olive groves." Ecological Economics 99: 63-73.

Scarpa, R. and M. Thiene (2005). "Destination Choice Models for Rock Climbing in the Northeastern Alps: A Latent-Class Approach Based on Intensity of Preferences." Land Economics 81(3): 426-444.

Torres, A. B., et al. (2015). "'Yes-in-my-backyard': Spatial differences in the valuation of forest services and local co-benefits for carbon markets in México." Ecological Economics 109: 130141.

Vermunt, J. K. and J. Magidson (2015). Technical Guide for Latent GOLD 5.1: Basic, Advanced, and Syntax, Belmont, MA: Statistical Innovations Inc.

Viscusi, W. K. and R. Zeckhauser (2006). "The Perception and Valuation of the Risks of Climate Change: A Rational and Behavioral Blend." Climatic Change 77(1-2): 151-177. 


\section{Appendix - Supplementary Tables}

Table A0. Performance of selection criterions for models with 2-10 classes, $\mathbf{n}=\mathbf{8 1 3}$

\begin{tabular}{|c|c|c|c|c|}
\hline $\begin{array}{l}\text { Number } \\
\text { classes }\end{array}$ & of Parameters & Log-Likelihood & $\mathrm{BIC}$ & AIC \\
\hline 2 & 8 & -5798.27 & 11650.15 & 11612.55 \\
\hline 3 & 17 & -4845.25 & 9804.40 & 9724.49 \\
\hline 4 & 26 & -4618.69 & 9411.60 & 9289.39 \\
\hline 5 & 35 & -4486.48 & 9207.48 & 9042.95 \\
\hline 6 & 44 & -4388.43 & 9071.68 & 8864.85 \\
\hline 7 & 53 & -4348.20 & 9051.54 & 8802.40 \\
\hline 8 & 62 & -4307.11 & 9029.67 & 8738.23 \\
\hline 9 & 71 & -4285.32 & 9046.39 & 8712.64 \\
\hline 10 & 80 & -4267.44 & 9070.95 & 8694.89 \\
\hline
\end{tabular}


Table A1. Descriptive statistics for attitude questions, percentage

\begin{tabular}{|c|c|c|c|c|}
\hline Attitude questions & Agree & Partly agree & $\begin{array}{l}\text { Partly } \\
\text { disagree }\end{array}$ & Disagree \\
\hline $\begin{array}{l}\text { Warm Glow } \\
\text { "I did not pay that much attention to the size } \\
\text { of the income effect, because I think the } \\
\text { most important thing is just to do } \\
\text { something" }\end{array}$ & 21.89 & 43.67 & 25.22 & 9.23 \\
\hline \multicolumn{5}{|l|}{ Altruists } \\
\hline $\begin{array}{l}\text { "When I made my choice, my objective was } \\
\text { to support climate policies that secured the } \\
\text { largest income gain, irrespective of which } \\
\text { region this effect befell." }\end{array}$ & 17.34 & 39.85 & 28.17 & 14.64 \\
\hline $\begin{array}{l}\text { Inequity Averse Altruists } \\
\text { "I often selected the climate policy that } \\
\text { secured the highest income gain for the poor } \\
\text { regions" }\end{array}$ & 10.82 & 39.98 & 34.44 & 14.76 \\
\hline Own Income & & & & \\
\hline $\begin{array}{l}\text { "When making my choices, I assumed that I } \\
\text { would also improve my own income during } \\
\text { my lifetime, through supporting climate } \\
\text { policies" }\end{array}$ & 7.26 & 34.07 & 35.18 & 23.49 \\
\hline Bequest Value & & & & \\
\hline $\begin{array}{l}\text { "I made my choices thinking about my } \\
\text { (future) grandchildren" }\end{array}$ & 24.60 & 40.96 & 16.61 & 17.84 \\
\hline
\end{tabular}




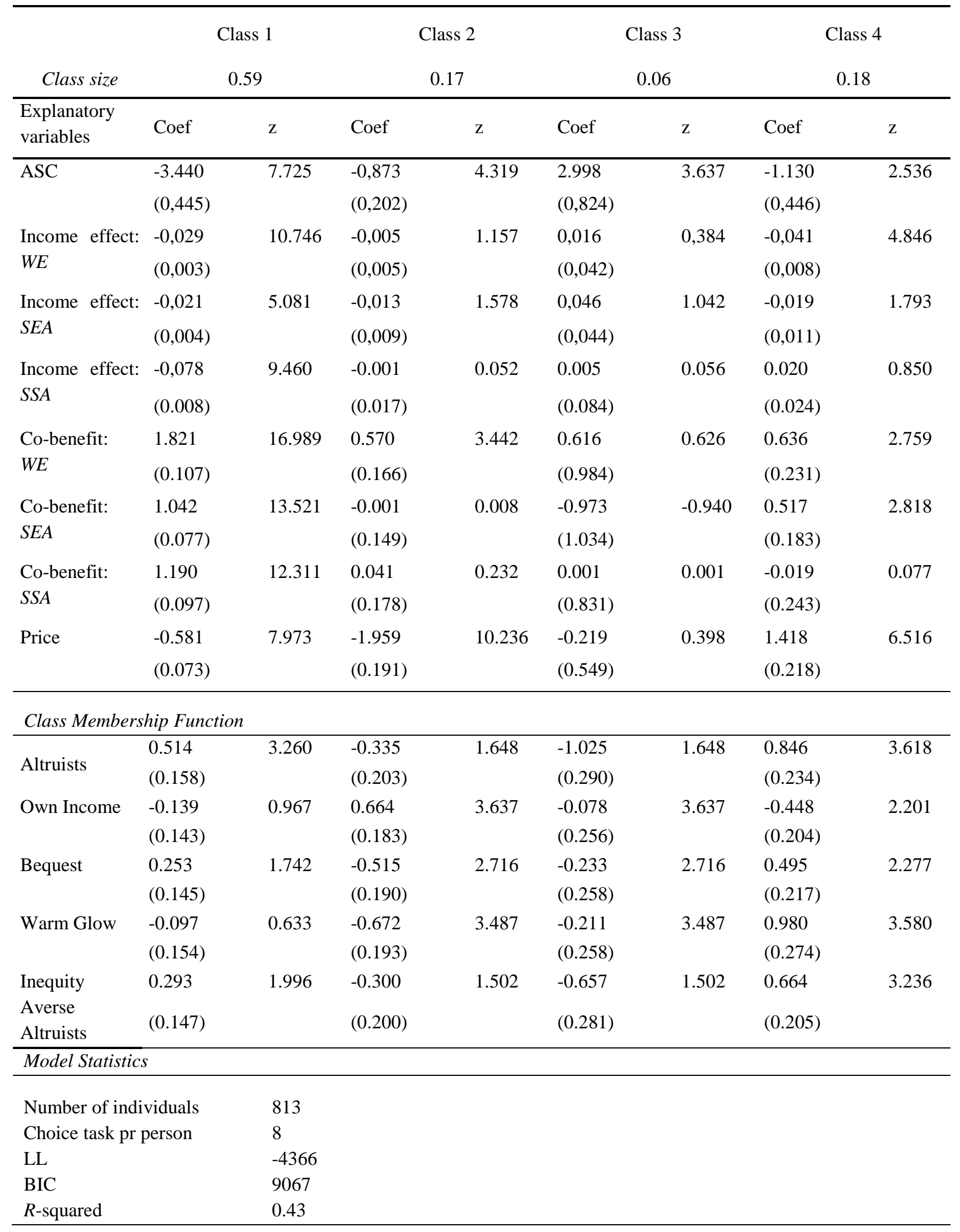


Table A3. Latent Class Model on subsample of respondent who answered the follow-up question correctly

\begin{tabular}{|c|c|c|c|c|c|c|c|c|}
\hline Class size & \multicolumn{2}{|c|}{$\begin{array}{c}\text { Class } 1 \\
0.58\end{array}$} & \multicolumn{2}{|c|}{$\begin{array}{c}\text { Class } 2 \\
0.09\end{array}$} & \multicolumn{2}{|c|}{$\begin{array}{c}\text { Class } 3 \\
0.09\end{array}$} & \multicolumn{2}{|c|}{$\begin{array}{c}\text { Class } 4 \\
0.24\end{array}$} \\
\hline $\begin{array}{l}\text { Explanatory } \\
\text { variables }\end{array}$ & Coef & $\mathrm{z}$ & Coef & $\mathrm{z}$ & Coef & $\mathrm{z}$ & Coef & $\mathrm{z}$ \\
\hline $\mathrm{ASC}$ & $\begin{array}{l}-3.985 \\
(0.705)\end{array}$ & 5.653 & $\begin{array}{l}-1.883 \\
(0.490)\end{array}$ & 3.841 & $\begin{array}{l}0.573 \\
(0.330)\end{array}$ & 1.737 & $\begin{array}{l}-1.474 \\
(0.419)\end{array}$ & 3.514 \\
\hline $\begin{array}{l}\text { Income effect: } \\
W E\end{array}$ & $\begin{array}{l}-0.034 \\
(0.004)\end{array}$ & 9.166 & $\begin{array}{l}-0.036 \\
(0.012)\end{array}$ & 2.982 & $\begin{array}{l}0.013 \\
(0.009)\end{array}$ & 1.365 & $\begin{array}{l}-0.031 \\
(0.006)\end{array}$ & 4.904 \\
\hline $\begin{array}{l}\text { Income effect: } \\
S E A\end{array}$ & $\begin{array}{l}-0.028 \\
(0.006)\end{array}$ & 4.831 & $\begin{array}{l}-0.058 \\
(0.020)\end{array}$ & 2.888 & $\begin{array}{l}-0.007 \\
(0.017)\end{array}$ & 0.437 & $\begin{array}{l}-0.011 \\
(0.011)\end{array}$ & 0.990 \\
\hline $\begin{array}{l}\text { Income effect: } \\
\text { SSA }\end{array}$ & $\begin{array}{l}-0.098 \\
(0.012)\end{array}$ & 8.293 & $\begin{array}{l}0.006 \\
(0.050)\end{array}$ & 0.116 & $\begin{array}{l}0.042 \\
(0.035)\end{array}$ & 1.189 & $\begin{array}{l}0.038 \\
(0.026)\end{array}$ & 1.458 \\
\hline $\begin{array}{l}\text { Co-benefit: } \\
W E\end{array}$ & $\begin{array}{l}1.939 \\
(0.142)\end{array}$ & 13.620 & $\begin{array}{l}0.633 \\
(0.508)\end{array}$ & 1.245 & $\begin{array}{l}0.502 \\
(0.296)\end{array}$ & 1.698 & $\begin{array}{l}0.988 \\
(0.235)\end{array}$ & 4.198 \\
\hline $\begin{array}{l}\text { Co-benefit: } \\
S E A\end{array}$ & $\begin{array}{l}1.048 \\
(0.103)\end{array}$ & 10.180 & $\begin{array}{l}-0.259 \\
(0.380)\end{array}$ & 0.775 & $\begin{array}{l}-0.944 \\
(0.351)\end{array}$ & 2.688 & $\begin{array}{l}0.758 \\
(0.191)\end{array}$ & 3.971 \\
\hline $\begin{array}{l}\text { Co-benefit: } \\
S S A\end{array}$ & $\begin{array}{l}1.315 \\
(0.133)\end{array}$ & 9.868 & $\begin{array}{l}-0.699 \\
(0.419)\end{array}$ & 1.670 & $\begin{array}{l}-0.335 \\
(0.306)\end{array}$ & 1.096 & $\begin{array}{l}0.323 \\
(0.242)\end{array}$ & 1.335 \\
\hline Price & $\begin{array}{l}-0.652 \\
(0.084)\end{array}$ & 7.740 & $\begin{array}{l}-4.469 \\
(0.692)\end{array}$ & 6.460 & $\begin{array}{l}-1.094 \\
(0.274)\end{array}$ & 3.995 & $\begin{array}{l}1.136 \\
(0.186)\end{array}$ & 6.094 \\
\hline \multicolumn{9}{|l|}{ Model Statistics } \\
\hline Number of indi & viduals & 518 & & & & & & \\
\hline Choice task pr $\mathrm{p}$ & person & 8 & & & & & & \\
\hline LL & & -2651 & & & & & & \\
\hline $\mathrm{BIC}$ & & 5522 & & & & & & \\
\hline$R$-squared & & 0.47 & & & & & & \\
\hline
\end{tabular}


Table A4. Latent Class Model with RPL specification for the co-benefits and price attributes

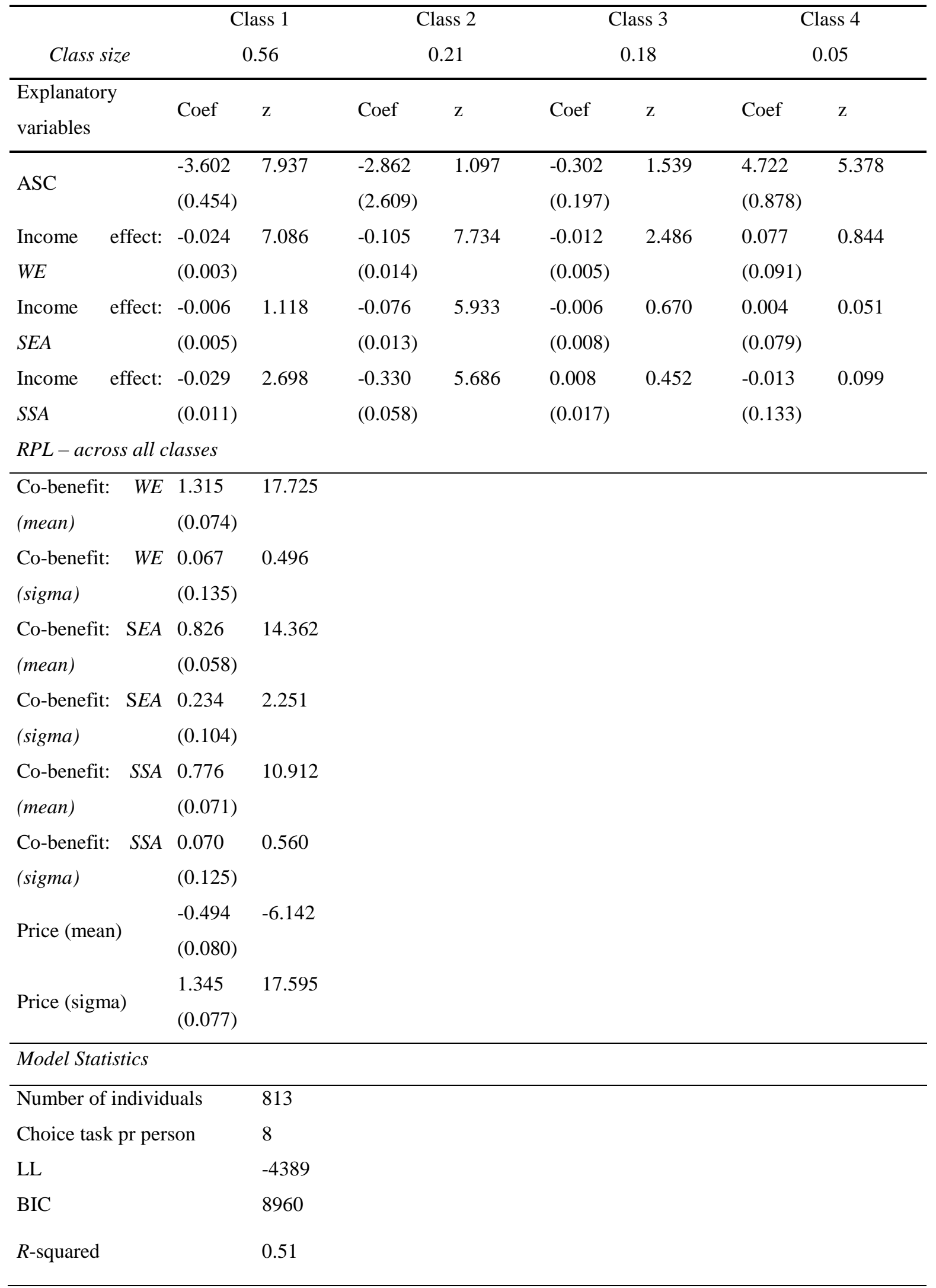

